\title{
MiniReVIEW
}

\section{Tissue Microarray Profiling of Cancer Specimens and Cell Lines: Opportunities and Limitations}

\author{
Axel Hoos and Carlos Cordon-Cardo \\ Departments of Surgery (AH) and Pathology (CC-C), Memorial Sloan-Kettering Cancer Center, New York, and \\ Antigenics, Inc. (AH), New York, New York
}

\begin{abstract}
SUMMARY: The implementations of high-throughput genetic technologies, such as oligonucleotide microarrays, generate myriad points of data. The identified potential candidate genes need to be further characterized and selected using a large number of well-characterized tumors and stringent criteria. Tissue microarrays allow for such high-throughput expression profiling of tumor samples, providing, in addition, information at the microanatomical level. Different techniques could be applied for identification of specific phenotypic (immunohistochemistry and in situ hybridization) or genotypic (fluorescence in situ hybridization) alterations, holding strong potential for translational research. Tissue microarrays consisting of 0.6-mm biopsies of paraffin-embedded tissues are well validated and have been used for various clinicopathological studies. This review discusses the technical considerations for construction of such arrays from paraffin-embedded tissues and cell lines and outlines their potential for clinical research applications. The use of paraffin-embedded tissues has some limitations with regard to analysis of RNA or certain proteins. To overcome such limitations, we have developed a cryoarray strategy allowing for the processing of multiple frozen tissue specimens and/or cell lines on a single tissue block. These approaches offer the opportunity to conduct pilot and validation studies of potential targets using clinical samples linked to clinicopathological databases. (Lab Invest 2001, 81:1331-1338).
\end{abstract}

$R$ ecent advances in genetics and biotechnology have brought up new classification schemes based on biological markers rather than anatomical definition regarding the clinical extent of the disease and morphological evaluation. Novel targets identified by analyses using the newly released human genome information (Lander et al, 2001; Venter et al, 2001), together with the development of microarray techniques that allow rapid large-scale screening (Kononen et al, 1998; Lockhart et al, 1996) and progress in bioinformatics with regard to processing and evaluation of complex data sets (Akutsu et al, 2000; Kruglyak and Lander, 1998; Lander et al, 1987), will still need to be further investigated. These studies will center in further defining their biological activities and clinicopathological relevance. Translational research will particularly benefit from these developments.

Tissue banks linked to comprehensive clinical databases, procured through patient consent and protected by stringent ethical criteria, will be one of the most crucial resources for discovery and validation studies. Molecular profiling of cancer using cDNA microarrays (Lockhart et al, 1996; Schena et

Received April 23, 2001

Address reprint requests to: Dr. Axel Hoos, Antigenics, Inc., 630 Fifth Ave., Suite 2100,NewYork, NY 10111.E-mail:AHoos@Antigenics.com al, 1995) further dissected by tissue microarraybased studies (Hoos et al, 2001b; Kononen et al, 1998) are expected to yield information of clinical significance. This may include the definition of new phenotypic profiles ascribed to certain disease entities, genes involved in critical cellular programs altered in particular tumors, and molecular targets of predictive or therapeutic value. For example, DNA microarrays can be used for the identification of subsets of expressed genes that would confirm or redefine a clinical entity, a pathological lesion, or a given disease stage (Emmert-Buck et al, 2000). These genes can subsequently be investigated for their expression in a large number of tumor and normal tissues using tissue microarrays linked to databases for rapid and reliable clinicopathological correlations (Moch et al, 1999).

Technical considerations and the potential of DNA microarrays have been thoroughly discussed in various publications within the last few years (Lipshutz et al, 1999; Lockhart and Winzeler, 2000). Tissue microarrays are now becoming a relevant tool for further characterizing information from DNA microarray studies (Mucci et al, 2000; Richter et al, 2000) (A Hoos, A Stojadinovic, R Ghossein, ME Dudas, D Kuo, DHY Leung, AR Shaha, MF Brennan, C Cordon-Cardo, and B Singh, unpublished data). This review summarizes our current experience with this field, discusses technical issues for tissue mi- 
croarray construction, and indicates opportunities and limitations for their application.

\section{Microarrays Using Paraffin-Embedded Tissues}

Conventional techniques for analysis of cancer specimens on the molecular level are labor intensive and time consuming. In the long run, they will not allow us to keep up with the rate at which new targets for tissue investigation are identified by DNA microarray analysis. The recently developed tissue microarray technology allows for high-throughput molecular profiling of tumor specimens by several techniques, including immunohistochemistry, fluorescence in situ hybridization and RNA in situ hybridization (Kononen et al, 1998). To construct a tissue microarray, small core biopsies are taken from viable, morphologically representative areas of paraffin-embedded tumor tissues and assembled on a recipient paraffin block. This is done with a precision instrument (Beecher Instruments, Silver Spring, Maryland) that uses two separate core needles for punching the donor and recipient blocks and a micrometer-precise coordinate system for tissue assembly on a multi-tissue block. During the recent evolution of the technique, initial large-core biopsies of over $3 \mathrm{~mm}$ in diameter were minimized to $0.6 \mathrm{~mm}$ in diameter. This size is sufficient for assessing morphological features of the analyzed tissues and allows the combination of up to 1000 cores on a single paraffin block. Microtome sections taken from such tissue microarray and placed on glass slides can be used for rapid and efficient molecular analyses. Besides tumor tissues, microarrays can contain corresponding normal tissues and internal controls, which can be analyzed in one experiment.

\section{Validation Strategies}

The main concern regarding the tissue microarray technique is that $0.6-\mathrm{mm}$ biopsies of tumor specimens on an array may not be representative of the whole tumor specimen because of tissue heterogeneity. In addition, if there were discrepancies between arrayderived and full-section-derived data, this may also lead to different results for clinicopathological correlations based on that data. Therefore, recent studies have determined the significance of molecular expression data derived from tissue microarrays relative to standard full-section analyses.

Two reports describe the validation of the tissue microarray technology with regard to the representative value of arrayed biopsies, the number of cores required per specimen, the complexity of immunophenotypes that can be reliably analyzed on tissue microarrays, and the use of data derived from tissue array for clinicopathological studies. One of these two studies centered on the investigation of 38 cases of breast carcinoma and their phenotypic profiles regarding estrogen receptor, progesterone receptor, and Her2/neu expression by immunohistochemistry, comparing 1 to 10 cores per specimen with full tissue sections (Camp et al, 2000). The results show that 2 -fold redundancy can lead to greater than $95 \%$ concordance between the two methods and that the addition of more cores increases concordance to $99.5 \%$ with 5 cores per specimen.

Some immuno-phenotypes can be very complex, and often clinicopathological studies require the application of cut-off values as used for full-section analysis of many markers (Drobnjak et al, 1994; Hoos et al, 2001a). Therefore, it is crucial to evaluate the number of cores required in conjunction with phenotype complexity. In a second study, 59 fibroblastic tumors were analyzed for their expression patterns of $\mathrm{Ki}-67$, p53, and the protein encoded by the retinoblastoma (RB) gene, or pRB (Hoos et al, 2001b). Cut-off values for considering a case positive or negative were $20 \%$ for Ki-67 and $10 \%$ for p53. The more complex phenotype of $\mathrm{pRB}$ included negative cases representing lack of protein expression because of genetic deletion or mutation, moderately positive cases representing wild-type $\mathrm{pRB}$ expression, and strongly positive cases representing the expression of hyperphosphorylated, nonfunctional protein (Cote et al, 1998). The results indicate that tumor heterogeneity can lead to lower concordance rates if more complex phenotypes are analyzed and that some cases may need to be excluded from the analysis if two cores with contradictory readings provide inconclusive data. The addition of a third core can improve concordance rates and prevent the exclusion of such cases because it allows a majority decision $(2>1)$. Overall, three cores per specimen resulted in concordance rates between $96 \%$ and $98 \%$ for readings distinguishing between two phenotypes, and $91 \%$ for the more complex three-category phenotype of pRB. Based on this data, it was concluded that binary phenotypes can be reliably investigated on tissue microarrays, whereas more complex phenotypes should still be analyzed on full-tissue sections. Because the use of different cut-off values in this study did not have a negative impact on the binary readings of $\mathrm{p} 53$ and $\mathrm{Ki}-67$, it can be assumed that full-section cut-off values can be used for tissue microarray-based analyses.

Because immunohistochemistry data are commonly used for identification of molecular markers that predict patient survival (Cordon-Cardo, 1997; Hoos et al, 2001a), the impact of data discrepancies between array and full-section with regard to patient outcome was also evaluated. As expected from the above results, this comparison did not show any significant change in clinicopathological correlations between the two methods, indicating that tissue microarrays may be reliable tools for high-throughput clinicopathological analyses of cancer specimens (Hoos et al, 2001b).

\section{Preparation of Microarrays Using Tissue Samples and Cell Lines}

Some technical aspects should be considered before the assembly of tissue and cell line arrays. If tissue arrays are constructed from tumor tissues, the targeting of a specific area representative for the specimen is crucial for the quality of the array. Hematoxylin/ 
eosin-stained full sections from the donor blocks must be obtained to assess morphology and to identify an area that represents the specimen. This can vary greatly among tissue types. For example, in colorectal cancer it is important that the target areas are small and well defined because stromal areas between the glandular structures of the tumor can be large and a core biopsy can easily miss the tumor-cell-rich regions (Fig. 1). In other malignancies like thyroid carcinoma, tumors can consist of relatively large nodules of densely packed cancer cells that can barely be missed by precise biopsies. In tissues with great intratumoral heterogeneity like soft tissue sarcomas, which often consist of alternating areas of high and low histologic grade, the targeting of high-grade regions appears important if immuno-phenotypes in these tissues are used for clinicopathological correlations including patient outcome. Figure 1 gives examples for tissue cores taken from such different cancer tissues with emphasis on their different morphological features. In cases where stroma-rich tumors with low numbers of cancer cells are arrayed, it may be necessary to use more than three cores per specimen to obtain meaningful results. For example, prostatic carcinoma preoperatively treated with radiation may consist only of a small number of remaining tumor cells scattered throughout the specimen.

We have recently shown that tissue arrays can also be constructed with paraffin-embedded cancer cell lines (A Hoos, H Petrowsky, A Culliford, CJ Di Como, ME Dudas, D Kuo, PB Paty, C Cordon-Cardo, and Y Fong, unpublished data). To obtain sufficiently dense and long cores of cells that can be transferred on a microarray, a few easy steps are recommended. Cells should be grown subconfluently in $500-\mathrm{cm}^{2}$ culture flasks, fixed in $10 \%$ formalin, subsequently incubated in $80 \%$ ethyl alcohol, and centrifuged in 0.6-ml Eppendorf tubes at $16,000 \times \mathrm{g}$. The resulting cylindrical pellets can be stably incubated in $80 \%$ ethyl alcohol overnight and embedded in the center of a paraffin block in a vertical position. Hematoxylin/eosin stains allow the assessment of cell pellet quality. The diameter of these cylindrical paraffin-embedded cell pellets allows at least three $0.6-\mathrm{mm}$ cores to be punched. Given the homogeneous character of these pellets, one core per cell line would probably be enough for immuno-phenotyping on a tissue array. Because the loss of cores during the cutting and staining process of these cell line arrays is similar to that observed in tissues (see next paragraph), we recommend that cell lines be arrayed in duplicate to avoid the loss of the specimen.

\section{Technical Considerations for Array Construction}

Some technical steps are crucial for the construction of a tissue microarray carrying paraffin-embedded tissues so that it can be a source for multiple highquality sections representing as many arrayed specimens as possible. Tissue loss during sectioning and staining is a common problem of the tissue array technique (Mucci et al, 2000; Richter et al, 2000;
Schraml et al, 1999). In addition, staining artifacts at the tissue borders are a well-known phenomenon in immunohistochemistry. Both occur most frequently in the periphery of the tissue microarray. To minimize the effect they may have on immunohistochemical results, we prefer to frame arrayed cancer specimens with one row of normal tissues. This technique has the advantages that the tumor tissues are centered on the array and protected by normal tissues and that peripheral staining artifacts involve normal tissues, not cancer specimens.

The orientation of the specimens on the array is crucial because confusion about their localization can threaten the evaluation of the experiment. For keeping the orientation of rows simple, we use different normal tissues to allow the identification of every row based on morphology. We use normal tissues with distinct morphology such as liver, kidney, thyroid, skeletal muscle, or colon mucosa (eg, Row 2 starts with thyroid and ends with liver, Row 3 starts with kidney and ends with skeletal muscle, etc.). In addition to this, we place two orientation cores in specific positions outside the geometric margins of the usually square or rectangular arrays to orient the entire microarray section after it has been cut (Fig. 2A).

The loss rate of assessable cases, resulting from tissue loss during cutting and transfer of array sections and vigorous staining procedures or because of inconclusive data, can be a significant factor of arraybased analysis. Previously reported rates of tissue damage range from $10 \%$ to more than $30 \%$ (Bubendorf et al, 1999; Hoos et al, 2001b; Mucci et al, 2000; Richter et al, 2000; Schraml et al, 1999). In our most recent analysis of Hürthle cell tumors of the thyroid gland, the rates of lost cases ranged from $3 \%$ to $18 \%$ for the different markers analyzed (A Hoos, A Stojadinovic, R Ghossein, ME Dudas, D Kuo, DHY Leung, AR Shaha, MF Brennan, C Cordon-Cardo, and B Singh, unpublished data). Loss of arrayed cases can be minimized without compromising the efficiency of the array technology by using three cores per tumor specimen, as indicated above. In addition, we use $0.6-\mathrm{mm}$ core diameters and $0.2-$ to $0.3-\mathrm{mm}$ spacing between the cores. In our experience, sectioning of the multi-tissue blocks has the lowest degree of tissue damage if performed without adhesive transfer tape. Another relevant factor that influences tissue loss rates is the quality of the tissue. If donor blocks were fixed for too long and tissues are dry, they are at higher risk of breaking into fragments than tissue that is in good condition. This factor cannot be reliably controlled because arrayed tissues can be decades old and tissue processing criteria can vary between specimens.

To get as many high-quality sections from one multi-tissue block as possible, it is advisable to array uniformly long tissue cores for each specimen. Unfortunately, this is not always possible because some donor tissues are thin and, therefore, do not allow the punching of long cores. To overcome this problem, more than one thin core from the same tumor area can be punched and one of them can be placed on top of 

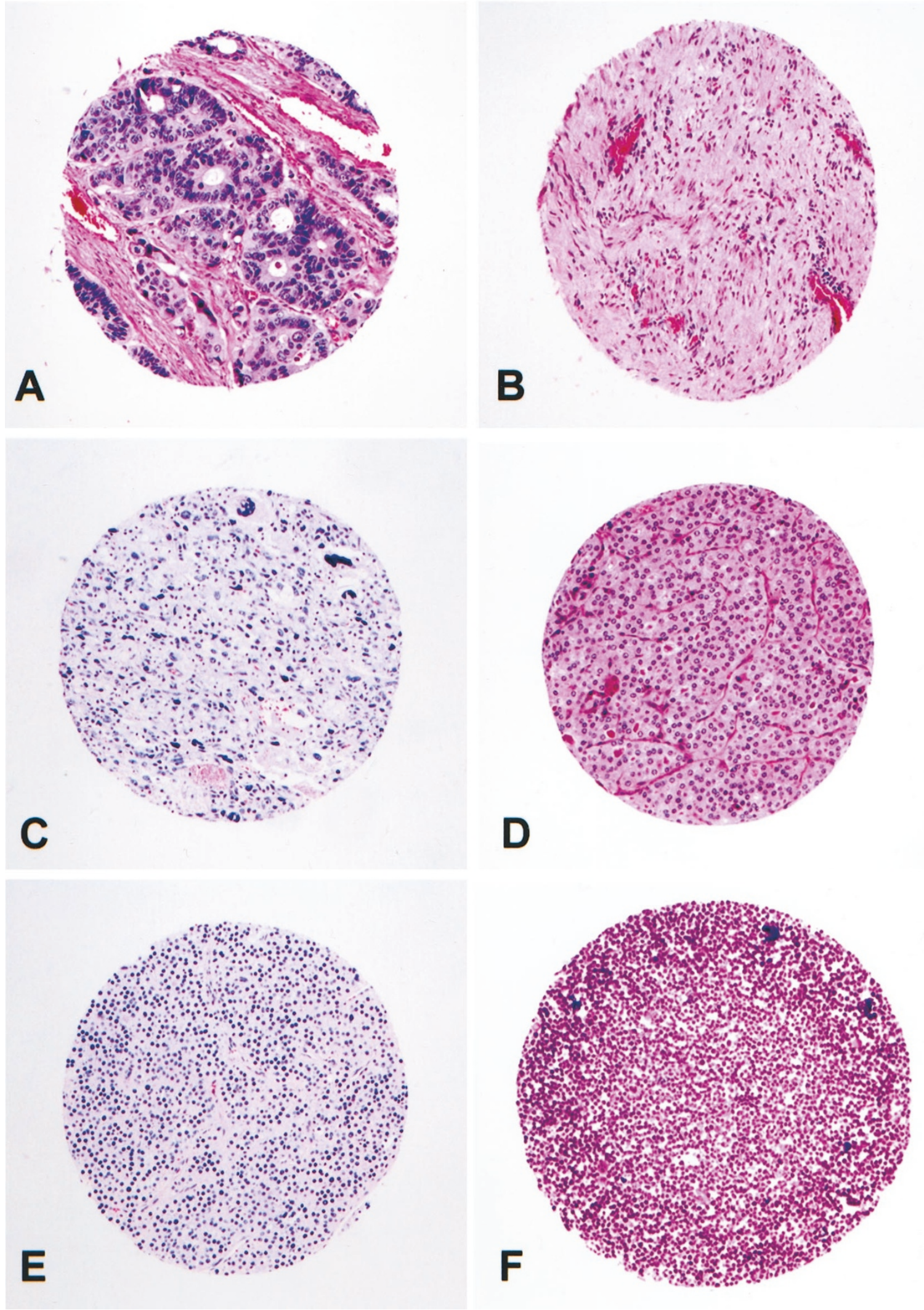

Figure 1.

Representative photomicrographs of hematoxylin/eosin-stained tissue cores assembled on tissue microarrays $(\times 100)$. Morphology of the arrayed tissues is crucial for the quality of the tissue microarray. A, Rectal cancer with glandular tumor architecture in the center of the core. B, A core taken from a rectal cancer specimen that was missing the glandular tumor structures. C, High-grade area of a soft tissue sarcoma potentially representative for the biological behavior of this lesion. D and $\mathrm{E}$, Tissue cores taken from tumor nodules of an oncocytic carcinoma of the thyroid (Hürthle cell carcinoma) (D) and a parathyroid tumor (E), both consisting of densely packed tumor cells. F, Core of a colorectal cancer cell line arrayed on a tissue microarray. 
A
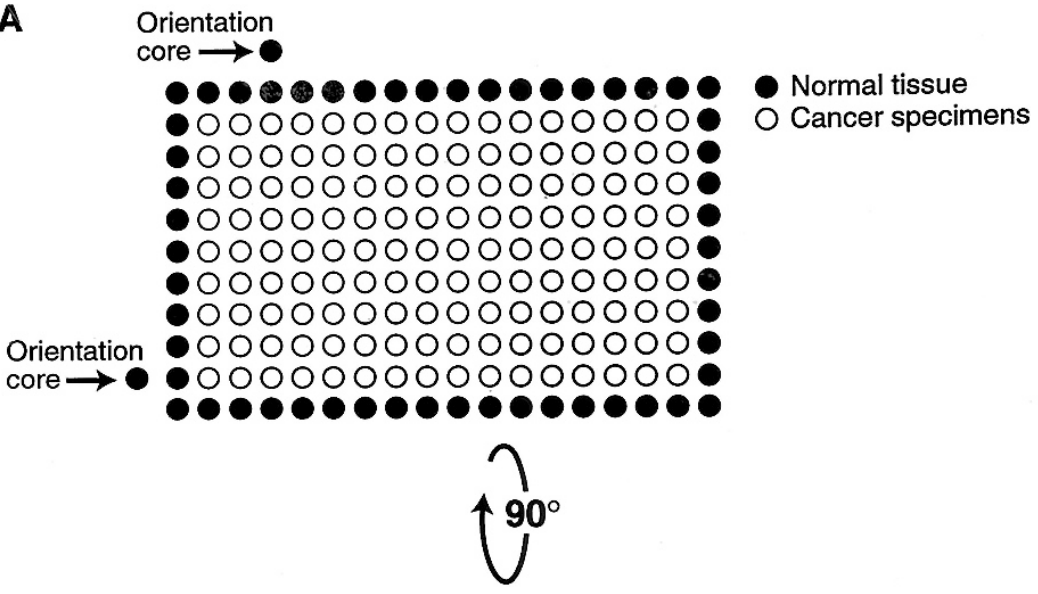

B

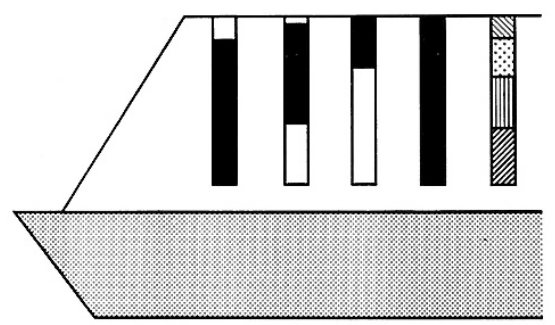

Figure 2.

A, General organization of our tissue microarrays. Cancer specimens are framed by one row of normal tissues with distinct morphology (eg, colon mucosa, liver, kidney, skeletal muscle). These normal tissues protect cancer specimens and allow identification of rows containing specific cancer cores. Two orientation cores are placed at specific points outside of the array to orient the whole specimen after sections are taken. B, Relevance of core length for tissue microarray integrity. Cores that are inserted too deeply into the recipient paraffin block will not be available on the first series of sections taken from the array (left). Cores not inserted to the bottom of the block could move inside the hole and could be missed by the microtome (second from left). Cores that are too short at the end will run out earlier than most full-length cores and are lost for the last series of sections from the array (center). Only full-length tissue cores can be reliably present on all sections (second from right). If tissues on the donor block are thin, a few thin cores from the same tumor area can be placed on top of each other to increase core length (right).

the other in the same location on the tissue array. Here, it is important to avoid the punching of tissue underlying paraffin, which can result in tissue-paraffin-tissue layers associated with higher loss rates. To avoid problems with micro-movement of cores in the punched holes of the multi-tissue block, cores should be inserted all the way to the bottom of the holes and completed tissue array blocks should be heated at $37^{\circ} \mathrm{C}$ for 30 minutes to make tissue cores and surrounding paraffin stick together tightly. Figure 2B depicts these varying possibilities for placing cores on the array.

\section{Tissue Microarrays Using Frozen Tissues (Cryoarrays)}

Paraffin-embedded tissues have distinct limitations for investigative molecular science attributable to fixatives and chemical reagents used in the paraffin process. This potentially impacts on the integrity of RNA, as well as on that of lipids and some proteins. Therefore, the previously described tissue microarray technology using paraffin-embedded tissues can reach its limits for the detection of RNA targets or certain proteins.

To overcome this limitation and to provide a tissue array system that allows DNA array and tissue arraybased analysis from the same specimens for direct comparison of the resulting data, we developed a cryoarray consisting of frozen tissues embedded in optimal cutting temperature compound (O.C.T.) (Sakura Finetek, Torrance, California). In our system, 48 biopsies taken from O.C.T.-embedded frozen tissues can be arrayed on one recipient block. This recipient block consists of a frame of O.C.T. containing 48 preformed holes with a diameter of $3.0 \mathrm{~mm}$ and is created as follows. A standard plastic mold for frozen tissue (Simport, Montreal, Canada; $37 \times 24$ $\mathrm{mm}$ ) is filled with liquid O.C.T. compound and a specifically designed cryoapparatus carrying 48 pins of 3-mm diameter is placed in the cryomold (Fig. 3A). These pins replace the O.C.T. compound and create a grid of holes framed by O.C.T. The mold is placed at $-80^{\circ} \mathrm{C}$ until the compound has solidified. At this point the cryoapparatus can be removed from the created recipient block by lowering an ejector plate over the pins of the cryoapparatus, thus releasing the O.C.T. block. Now, a specifically designed core biopsy needle of 3-mm diameter (Fig. 3B) is used to punch specimens from identified areas of the donor frozen tissue blocks and transfer them to the recipient block in a manner similar to that for paraffin-embedded tissues (Kononen et al, 1998). The further processing of such a tissue array follows the general guidelines for O.C.T.-embedded frozen tissue samples. 
A

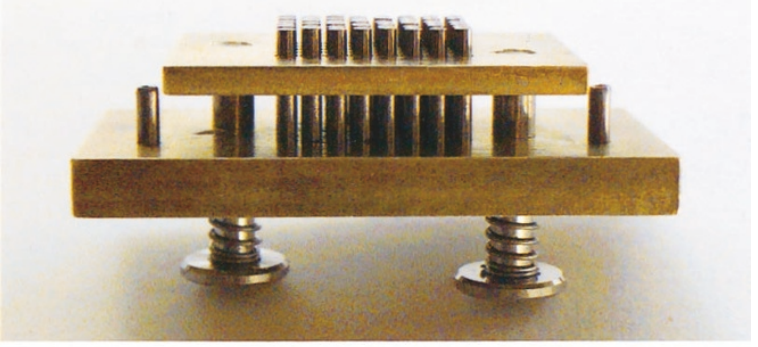

B

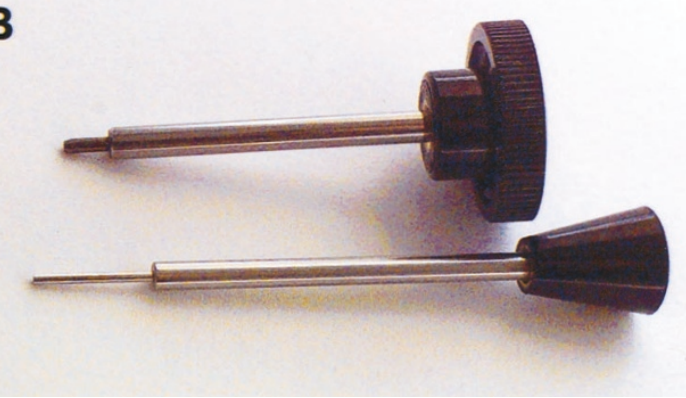

Figure 3.

A, Cryoapparatus carrying 48 pins of $3 \mathrm{~mm}$ diameter and an ejector plate that can be lowered over the pins to release an optimal cutting temperature (O.C.T.) block with 48 preformed holes. In these preformed holes, 48 biopsies taken from 0.C.T.-embedded frozen tissues can be placed and thus arrayed on one 0.C.T. block. The cryoapparatus is shown from below in a position where the ejector plate is lowered halfway over the pins. B, Biopsy needle of $3 \mathrm{~mm}$ diameter for the punching of O.C.T.-embedded specimens. The strong core needle (top) is used to punch a hole in the identified area of the donor block, and the piston (bottom) is inserted into the core needle and is used to release the punched core into one of the preformed holes of the 48-core cryoarray.

This technology has the potential to overcome the problems of tissue microarrays with paraffin-embedded tissues. Even if the number of specimens that can be analyzed per array is lower than that with paraffin tissue arrays, the cryoarray system provides a significant advantage over standard frozen section analysis. Because of the core diameter of $3 \mathrm{~mm}$ in cryoarrays, it may not be necessary to array more than one or two biopsies per specimen, thus increasing the efficiency in comparison with paraffin tissue arrays (Fig. 4). Because of the novel character of this technology, we are currently in the process of evaluating the criteria for its use and seeking to optimize tissue handling for best possible array quality.

\section{Perspective}

Tissue microarrays carrying three cores of paraffinembedded tumors per specimen deliver accurate results and allow economic high-throughput processing of cancer specimens and other tissues. This technology has the potential to accelerate translational research and to efficiently analyze tissue expression of genes identified by DNA microarray studies. In addition, multi-cell-line arrays are useful for rapid characterization of the expression profiles of multiple cell lines relevant for cancer research. Both tissue and cell line arrays are powerful tools for the screening of new reagents like hybridization probes and antibodies. The standardization of staining procedures and reduction of intra-assay variability can also be significantly improved with this technique. Tissue microarrays are useful for establishing large disease-specific tissue collections for future analysis of new targets in a particular tumor entity and can be helpful for collaborations between major institutions.

The limitations of tissue microarrays using paraffin-embedded tissues can be overcome with cryoarrays containing frozen tissue biopsies. Cryoarrays could prove relevant for high-throughput analysis of frozen tissues for expression profiling of mRNA and certain proteins. They can also be used
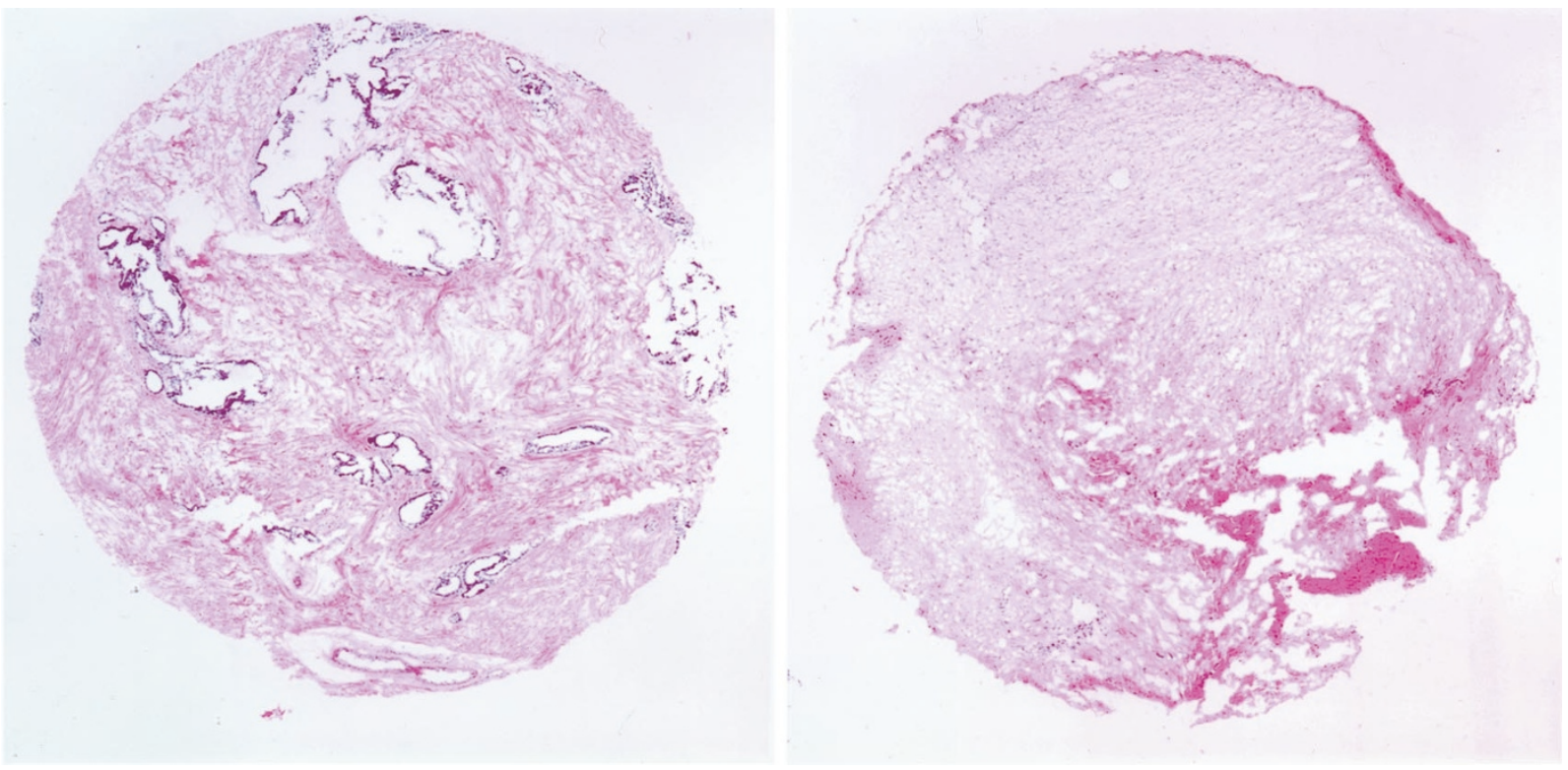

Figure 4.

Photomicrograph of two hematoxylin/eosin-stained 3-mm frozen tissue cores. The left core shows normal prostate and the right core a desmoid tumor. 
for the investigation of tissues from which RNA was extracted for cDNA array analysis, thus allowing a direct comparison of expression profiles obtained from both techniques. The limitations of this new technique need to be further evaluated.

The new tissue microarray techniques can be used for various different array designs, for example, progression arrays containing precursor lesions of cancer and cancer specimens of lesions with increasing aggressiveness, tissue-type comparative arrays containing normal, benign, and malignant specimens from the same tissue type, or cancer arrays containing different subtypes or stages of the same tumor entity. An example of a tissue array of different variants of breast cancer was recently described (Hedenfalk et al, 2001). In this study, 113 cases of breast cancer were placed on a tissue microarray and analyzed for protein expression levels of two molecules that were identified to be differentially expressed between BRCA-1 and BRCA-2 mutation-positive tumors by cDNA microarray analysis. The results confirmed the expression patterns in these two tumor groups to be the same on the protein level as on the RNA level. This study can serve as a good example for the combined use of cDNA and tissue microarrays. Taken together, tissue microarrays are powerful tools for future endeavors in translational cancer research and could prove useful for other applications we have not even considered.

\section{References}

Akutsu T, Miyano S, and Kuhara S (2000). Inferring qualitative relations in genetic networks and metabolic pathways. Bioinformatics 16:727-734.

Bubendorf L, Kononen J, Koivisto P, Schraml P, Moch H, Gasser TC, Willi N, Mihatsch MJ, Sauter G, and Kallioniemi OP (1999). Survey of gene amplifications during prostate cancer progression by high-throughput fluorescence in situ hybridization on tissue microarrays. Cancer Res 59: 803-806.

Camp RL, Charette LA, and Rimm DL (2000). Validation of tissue microarray technology in breast carcinoma. Lab Invest 80:1943-1949.

Cordon-Cardo C (1997). Mutation of cell cycle regulators. Biological and clinical implications for human neoplasia. Am J Pathol 147:545-560.

Cote RJ, Dunn MD, Chatterjee SJ, Stein JP, Shi SR, Tran QC, Hu SX, Xu HJ, Groshen S, Taylor CR, Skinner DG, and Benedict WF (1998). Elevated and absent pRB expression is associated with bladder cancer progression and has cooperative effects with p53. Cancer Res 58:1090-1094.

Drobnjak M, Latres E, Pollack D, Karpeh M, Dudas M, Woodruff JM, Brennan MF, and Cordon-Cardo C (1994). Prognostic implications of p53 nuclear overexpression and high proliferation index of $\mathrm{Ki}-67$ in adult soft tissue sarcomas. J Natl Cancer Inst 86:549-554.

Emmert-Buck MR, Strausberg RL, Krizman DB, Bonaldo MF, Bonner RF, Bostwick DG, Brown MR, Buetow KH, Chuaqui RF, Cole KA, Duray PH, Englert CR, Gillespie JW, Greenhut S, Grouse L, Hillier LW, Katz KS, Klausner RD,
Kuznetzov V, Lash AE, Lennon G, Linehan WM, Liotta LA, Marra MA, Munson PJ, Ornstein DK, Prabhu VV, Prange C, Schuler GD, Soares MB, Tolstoshev CM, Vocke CD, and Waterston $\mathrm{RH}$ (2000). Molecular profiling of clinical tissue specimens: Feasibility and applications. Am J Pathol 156: 1109-1115.

Hedenfalk I, Duggan D, Chen Y, Radmacher M, Bittner M, Simon R, Meltzer P, Gusterson B, Esteller M, Kallioniemei OP, Wilfond B, Borg A, and Trent J (2001). Gene-expression profiles in hereditary breast cancer. N Engl J Med 344:539548 .

Hoos A, Lewis JJ, Antonescu CR, Dudas ME, Leon L, Woodruff JM, Brennan MF, and Cordon-Cardo C (2001a). Characterization of molecular abnormalities in human fibroblastic neoplasms -a model for genotype-phenotype association in soft tissue tumors. Cancer Res 61:31713175.

Hoos A, Urist MJ, Stojadinovic A, Mastorides S, Dudas M, Kuo D, Leung DHY, Brennan MF, Lewis JJ, and CordonCardo C (2001b). Validation of tissue microarrays for immunohistochemical profiling of cancer specimens using the example of human fibroblastic tumors. Am J Pathol 158: 1245-1251.

Kruglyak L and Lander ES (1998). Faster multipoint linkage analysis using Fourier transforms. J Comput Biol 5:1-7.

Kononen J, Bubendorf L, Kallioniemi A, Barlund M, Schraml, P, Leighton S, Torhorst J, Mihatsch MJ, Sauter G, and Kallioniemi OP (1998). Tissue microarrays for highthroughput molecular profiling of tumor specimens. Nat Med $4: 844-847$

Lander ES, Green P, Abrahamson J, Barlow A, Daly MJ, Lincoln SE, and Newburg L (1987). MAPMAKER: An interactive computer package for constructing primary genetic linkage maps of experimental and natural populations. Genomics 1:174-181.

Lander ES, Linton LM, Birren B, Nusbaum C, Zody MC, Baldwin J, et al (2001). Initial sequencing and analysis of the human genome. Nature 409:860-921.

Lipshutz RJ, Fodor SP, Gingeras TR, and Lockhart DJ (1999). High-density synthetic oligonucleotide arrays. Nat Genet 21:20-24.

Lockhart DJ and Winzeler EA (2000). Genomics, gene expression, and DNA arrays. Nature 405:827-836.

Lockhart DJ, Dong H, Byrne MC, Follettie MT, Gallo MV, Chee MS, Mittmann M, Wang C, Kobayashi M, Horton H, and Brown EL (1996). Expression monitoring by hybridization to high density oligonucleotide arrays. Nat Biotechnol 14:16751680 .

Moch H, Schraml P, Bubendorf L, Mirlacher M, Kononen J, Gasser T, Mihatsch MJ, Kallioniemi OP, and Sauter G (1999). High-throughput tissue microarray analysis to evaluate genes uncovered by cDNA microarray screening in renal cell carcinoma. Am J Pathol 154:981-986.

Mucci NR, Akdas G, Manely S, and Rubin MA (2000). Neuroendocrine expression in metastatic prostate cancer: Evaluation of high throughput tissue microarrays to detect heterogeneous protein expression. Hum Pathol 31:406414.

Richter J, Wagner U, Kononen J, Fijan A, Bruderer J, Schmid $\mathrm{U}$, Ackermann D, Maurer R, Alund G, Knonagel H, Rist M, Wilber K, Anabitarte M, Hering F, Hardmeier T, Schonen- 
berger A, Flury R, Jager P, Fehr JL, Schraml $P$, Moch $H$, Mihatsch MJ, Gasser T, Kallioniemi OP, and Sauter G (2000). High-throughput tissue microarray analysis of cyclin $E$ gene amplification and overexpression in urinary bladder cancer. Am J Pathol 157:787-794.

Schena M, Shalon D, Davis RW, and Brown PO (1995). Quantitative monitoring of gene expression patterns with complimentary DNA microarray. Science 270:467-470.
Schraml P, Kononen J, Bubendorf L, Moch H, Bissig $H$, Nocito A, Mihatsch MJ, Kallioniemi OP, Sauter G (1999). Tissue microarrays for gene amplification surveys in many different tumor types. Clin Cancer Res 5:1966-1975.

Venter JC, Adams MD, Myers EW, Li PW, Mural RJ, Sutton $G G$, et al (2001). The sequence of the human genome. Science 291:1304-1351.

\section{ERRATUM}

Please note the following corrections to the article entitled "Multiplex detection of hotspot mutations by rolling circle-enabled universal microarrays" Ladner et al, Vol 81, No 8, pp1079-1086, appearing in the August 2001 issue:

- In the legend to Figure 2 ( $p$ 1081), the description of frames A and B is incorrect (reversed). It should read thus:

A, Without RCA amplification, when a Cy-3 fluorophore is directly attached to the downstream probe, only wild-type DNA can be detected, whereas the GAT mutation remains undetectable. B, With RCA signal amplification, both the GGT wt and the GAT mutation where correctly detected.

- Grant footnote was incomplete ( $p$ 1079). It should read thus:

This work was supported by the NCl Early Detection Research Network Grant No. CA 85065-03 and the NCl Innovative Technologies Grant No. CA81671-02. 